\title{
Hydrothermal Synthesis of Leaf-Shaped Ferric Oxide Particles
}

\author{
KEQIANG DING \\ Chemistry \& Material Science College, \\ Hebei Normal University, Shijiazhuang- 050016, P.R. China. \\ dkeqiang@263.net
}

Received 19 October 2008; Accepted 12 December 2008

\begin{abstract}
For the first time, leaf-shaped ferric oxide particles were prepared from an aqueous solution of potassium ferricyanide $\left[\mathrm{K}_{3} \mathrm{Fe}(\mathrm{CN})_{6}\right]$ by hydrothermal process. Images obtained from SEM (scanning electron microscope) revealed that leaf-shaped ferric oxides (around $1.5 \mu \mathrm{m}$ in length) were clearly exhibited when the hydrothermal tempreature was $150^{\circ} \mathrm{C}$, while as the temperature was increased to $200{ }^{\circ} \mathrm{C}$ leaf-shaped ferric oxide particles with larger size were observed. XRD (X-ray diffraction) patterns testified that the obtained ferric oxides were $\alpha-\mathrm{Fe}_{2} \mathrm{O}_{3}$ with well-structured crystal faces. Interestingly, histograms describing the distribution of samples indicated that the distribution of obtained ferric oxide particles did not accord with gaussian distribution
\end{abstract}

Keywords: Microstructure, Leaf-shaped particles, Crystal structure, Hydrothermal synthesis.

\section{Introduction}

Iron oxides, as the main super paramagnetic material, can offer a great potential applications in different areas such as ferrofluids, color imaging, magnetic refrigeration, detoxification of biological fluids, magnetically controlled transport of anti-cancer drugs, magnetic resonance imaging and magnetic cell separation ${ }^{1}$. Many methods were developed to generate ferric oxides, including gel-sol processing ${ }^{2,3}$, forced hydrolysis processing ${ }^{4,5}$, hydrothermal processing treatments ${ }^{6,7}$, electrochemical deposition ${ }^{8}$. Among these developed ways, thermal decomposition route is the commonly selected method due to its several advantages (a) effective control of size and shape of the particles; (b) easy manipulation and shorter preparation time; (c) fewer impurities in the final products. Hydrothermal treatment of iron salt could prepare iron oxides as the preparation conditions were appropriate, for example, Wang group reported the synthesis and magnetic properties of $\mathrm{Fe}_{3} \mathrm{O}_{4}$ in which 
$\mathrm{Fe}(\mathrm{CN})_{3} \cdot 9 \mathrm{H}_{2} \mathrm{O}$ was utilized as the iron-contained precursor ${ }^{9}$. Professor Musić discussed the effects of urotropin on the chemical and micro structural properties of $\mathrm{Fe}$-oxide powders that were prepared by the hydrolysis of aqueous $\mathrm{FeCl}_{3}$ solution ${ }^{10}$. Meanwhile, $\alpha-\mathrm{Fe}_{2} \mathrm{O}_{3}$ were also widely investigated, e.g., Professor Yan reported ${ }^{11}$ the hierarchical assembly of $\mathrm{SnO}_{2}$ nanorod arrays on $\alpha-\mathrm{Fe}_{2} \mathrm{O}_{3}$. Research group led by Professor Ulman demonstrated that doped $\mathrm{Mn}(\mathrm{III})$ could suppress the transition from $\gamma-\mathrm{Fe}_{2} \mathrm{O}_{3}$ nanoparticles to the $\alpha-\mathrm{Fe}_{2} \mathrm{O}_{3}$ structure $^{12}$. Ferric oxide particles of many shapes, including spheres, cubes, rods, platelets and spindles, were all prepared ${ }^{13}$. To the best of our knowledge, till now, there is no paper reporting the preparation of leaf-shaped iron oxide particles.

In this hydrothermal process, potassium ferricyanide aqueous solution were kept in a Teflon-lined autoclave at the required temperatures for $3 \mathrm{~h}$, in which except for water and potassium ferricyanide, no other reductive reagents were introduced. Subsequently, after $48 \mathrm{~h}$ sedimentation at room temperature, leaf-shaped ferric oxides with well-structured crystals were formed, which are novel phenomena that have never been reported so far.

\section{Experimental}

\section{Preparation of ferric oxide particles}

All the chemicals were analytical grade and used without further purification. In this experiment, $20 \mathrm{~mL}$ aqueous solution containing $5 \times 10^{-3} \mathrm{M}$ potassium ferricyanide was placed in a Teflon-lined autoclave first, and then this sealed autoclave was placed in an oven at room temperature, subsequently, the temperature of oven was increased to $150{ }^{\circ} \mathrm{C}$ or $200{ }^{\circ} \mathrm{C}$ within $20 \mathrm{~min}$ and then the temperature was kept for $3 \mathrm{~h}$. After $48 \mathrm{~h}$ sedimentation at room temperature, the resultant products were washed by redistilled water carefully and dried by ambient air successively. Lastly, the obtained particles were directly used for characterization.

\section{Characterization}

The morphology of obtained ferric oxide particles were characterized by a Hitachi model S570 scanning electron microscope (SEM). X-ray diffraction (XRD) patterns were recorded on a Bruker D8 Advance diffractometer (Germany) with $\mathrm{Cu} \mathrm{K \alpha}$ as the radiation source $(\lambda=0.154 \mathrm{~nm})$, the $2 \theta$ range used in this measurement was from $5^{\circ}$ to $85^{\circ}$. Particle size distribution was measured on a JL-1155 laser particle analyser (Chengdu Jinxin Instrument Co., Ltd (China)). FT-IR spectrum was recorded on a Fourier transform infrared spectrometry (1730, P-E, USA).

\section{Results and Discussion}

The typical digital photoes for the samples are presented in Figure 1, where the yellow solution, i.e., A1, is potassium ferricyanide solution of $5 \times 10^{-3} \mathrm{M}$, and the beaker containing red particles obtained at $150{ }^{\circ} \mathrm{C}$ is denoted as $\mathrm{A} 2$, samples obtained at $200{ }^{\circ} \mathrm{C}$ is denoted as A3. One can see that after hydrothermal process, some red particles were formed at the bottom of the beaker, and as the temperature was $200{ }^{\circ} \mathrm{C}$ the solution became transparent, as shown by A3 in Figure 1, suggesting that iron element in potassium ferricyanide was totally converted into the resultant particles by this hydrothermal process.

To our surprise, the leaf-shaped particles are clearly observed by SEM images as shown in Figure 2. Figure $2 \mathrm{~A}$ is the resultant products obtained at $150{ }^{\circ} \mathrm{C}$ where well-structured leaf-shaped particles are exhibited, as shown by the circled leaf. While as the hydrothermal 
temtperature is $200{ }^{\circ} \mathrm{C}$ as shown by Figure $2 \mathrm{~B}$, more larger leaf-shaped particles are observed at the same magnification, indicating that when the temperature is $200{ }^{\circ} \mathrm{C}$ more iron elements were transferred into the products and thus in the same sedimentation time, more larger particles of ferric oxide were formed. To our knowledge, this is the first time to report the leaf-shaped ferric oxide particles

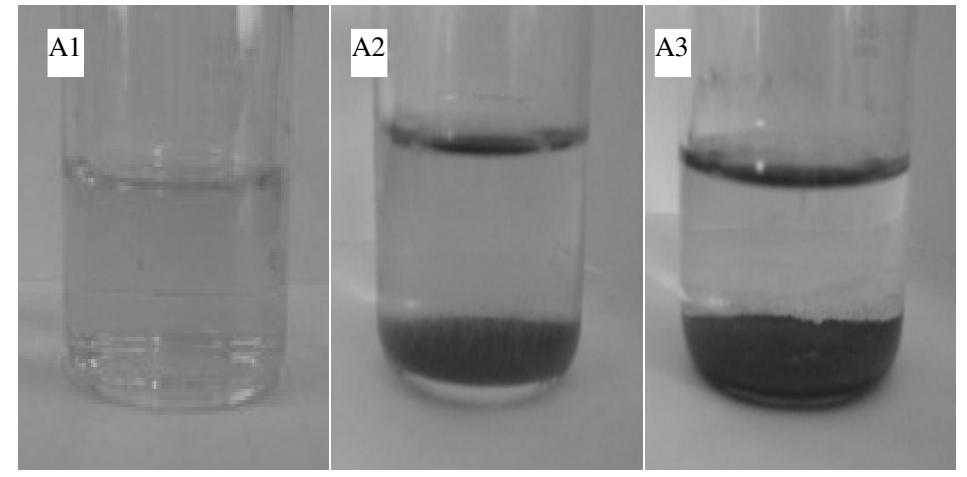

Figure 1. Digitals photoes for the as-prepared samlpes. A1: $5 \times 10^{-3} \mathrm{M} \mathrm{K}_{3} \mathrm{Fe}(\mathrm{CN})_{6}$ aqueous solution, A2: samples obtained at $150{ }^{\circ} \mathrm{C}$; A3: obtained at $200{ }^{\circ} \mathrm{C}$.
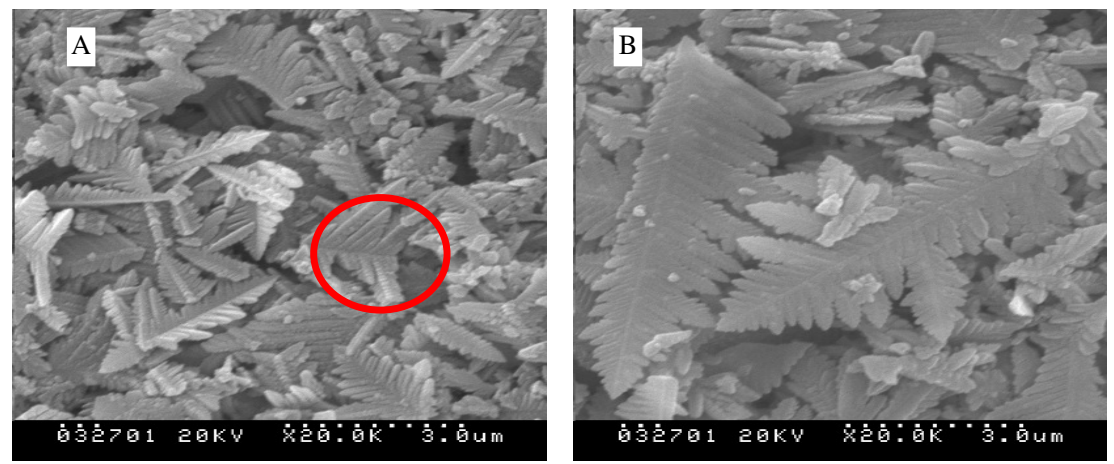

Figure 2. SEM images of the resultant leaf-shaped particles prepared at various temperature: (A) $150{ }^{\circ} \mathrm{C}$ (B) $200{ }^{\circ} \mathrm{C}$.

Figure 3 shows the XRD patterns of the resultant particles. All diffraction peaks can be perfectly indexed to $\alpha-\mathrm{Fe}_{2} \mathrm{O}_{3}$ (JCPSD 33-664), according with the former report very well ${ }^{13}$. Two patterns that obtained at different temperature are very similar, and the intensities of diffraction peaks become stronger for the samples obtained at $200{ }^{\circ} \mathrm{C}$ (as shown by Figure 3A) when compared to the samples obtained at $150{ }^{\circ} \mathrm{C}$ (as shown by Figure $3 \mathrm{~B}$ ), suggesting that $200{ }^{\circ} \mathrm{C}$ is beneficial to the formation of ferric oxides with well-structured crystal faces.

Particle size distribution of the resultant particles was also measured, as illustrated by the histogram in Figure 4, where the white rods represent the distribution of samples prepared at $150{ }^{\circ} \mathrm{C}$, and the red rods correspond to the samples obtained at $200{ }^{\circ} \mathrm{C}$. Generally, particle size distribution should tally with the gaussian distribution, for instance, the research group led by Abd-Shukor ${ }^{14}$ reported the histogram of $\mathrm{Fe}_{3} \mathrm{O}_{4}$ particles prepared by the pyrolysis reaction of organometallic compound, in which particle size distribution accorded 
with the gaussian distribution very well. While, in our work, it can be seen from Figure 4 that the particle size distribution does not accord with gaussian distribution, i.e., particles with the larger diameter are the main part of the resultant particles, indicating that there should be a crystal growth process during the sedimentation process after hydrothermal treatment.
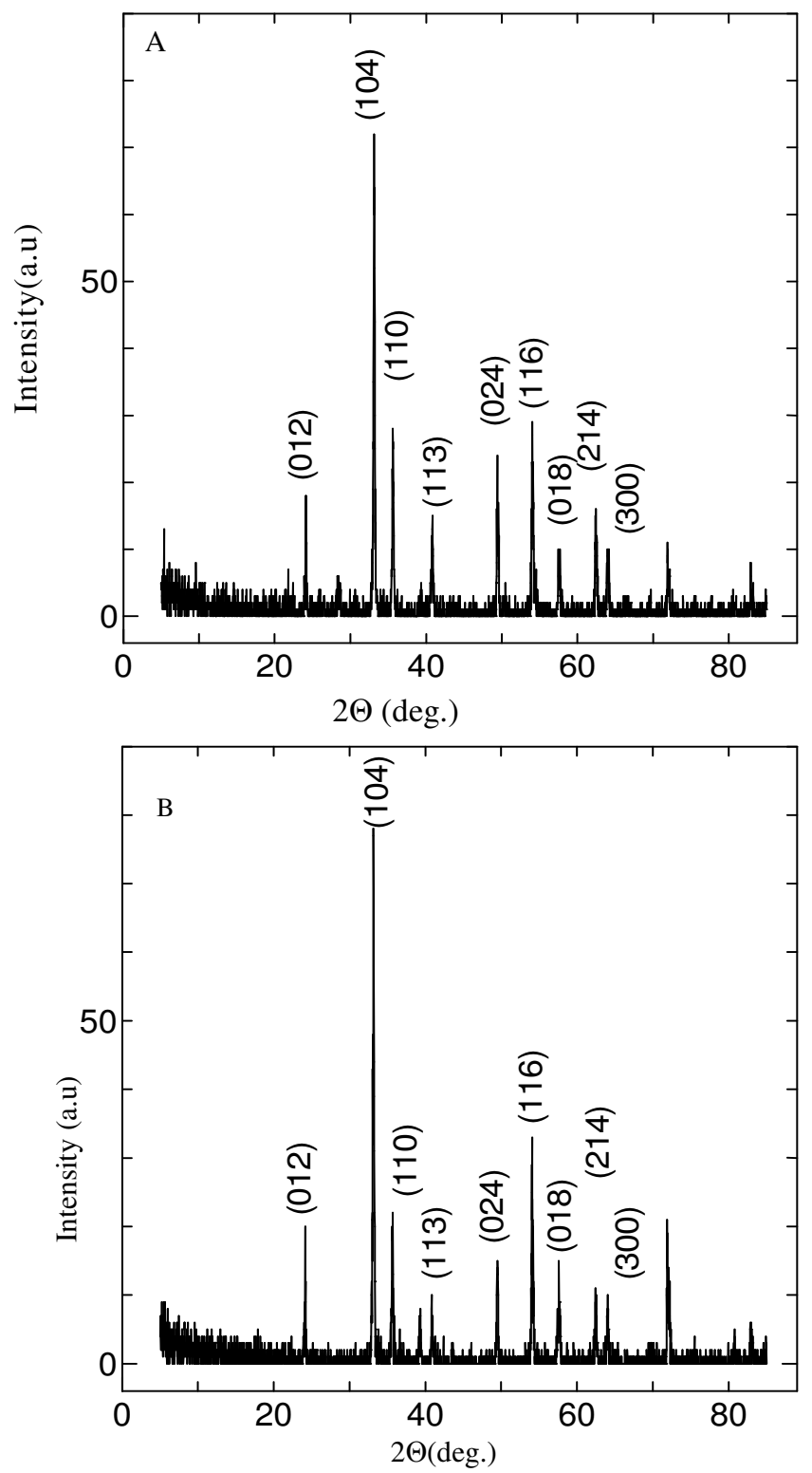

Figure 3. XRD patterns of $\alpha-\mathrm{Fe}_{2} \mathrm{O}_{3}$ particles prepared at different temperatures, (A) $150{ }^{\circ} \mathrm{C}$ (B) $200{ }^{\circ} \mathrm{C}$. 


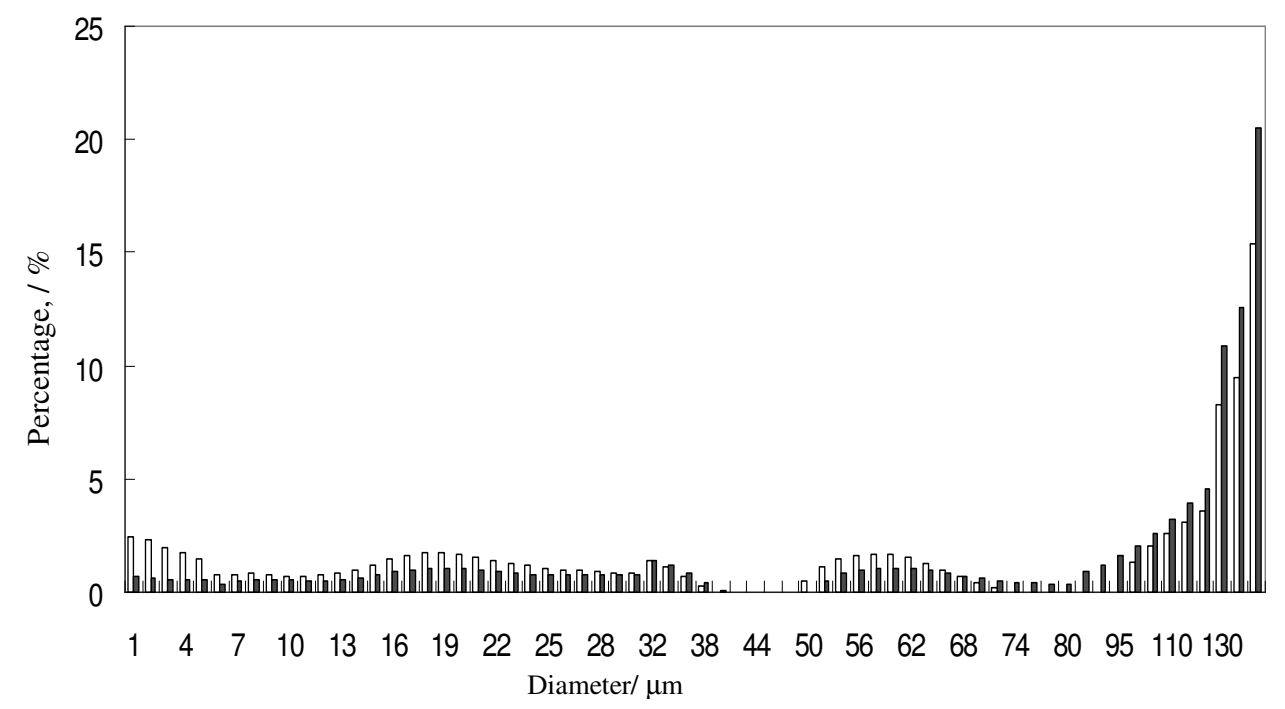

Figure 4. Curve of particle size versus frequency distribution, white bar: obtained at $150{ }^{\circ} \mathrm{C}$; red bar: obtained at $200{ }^{\circ} \mathrm{C}$

FT-IR spectroscopy is another powertul tecnnique to teature iron oxides. Figure $5 \mathrm{~A} \&$ 5B correspond to the FT-IR spectra of particles prepared at $150{ }^{\circ} \mathrm{C}$ and $200{ }^{\circ} \mathrm{C}$, respectively. Two similar spectra were exhibited, consistent with the XRD plots presented in Figure 3 very well. Zheng et $a l^{9}$ has pointed that the spectroscopic bands located at $580 \mathrm{~cm}^{-1}$ were related to the vibration of $\mathrm{Fe}-\mathrm{O}$ functional group. Moreover, since the shape of our obtained IR spectra is similar to the IR spectra presented Zheng et al ${ }^{9}$, thus the spectroscopic peak located at 530.4 (or 528.5 ) $\mathrm{cm}^{-1}$ and 451.3 (or 447.5 ) $\mathrm{cm}^{-1}$ are the characteristic absorption bands of ferric oxides. For the absorption peaks at 1616 and $1400 \mathrm{~cm}^{-1}$, generally, they are assigned to the asymmetrical and symmetrical stretching vibration of carboxylate $(\mathrm{O}-\mathrm{C}=\mathrm{O})^{15}$.
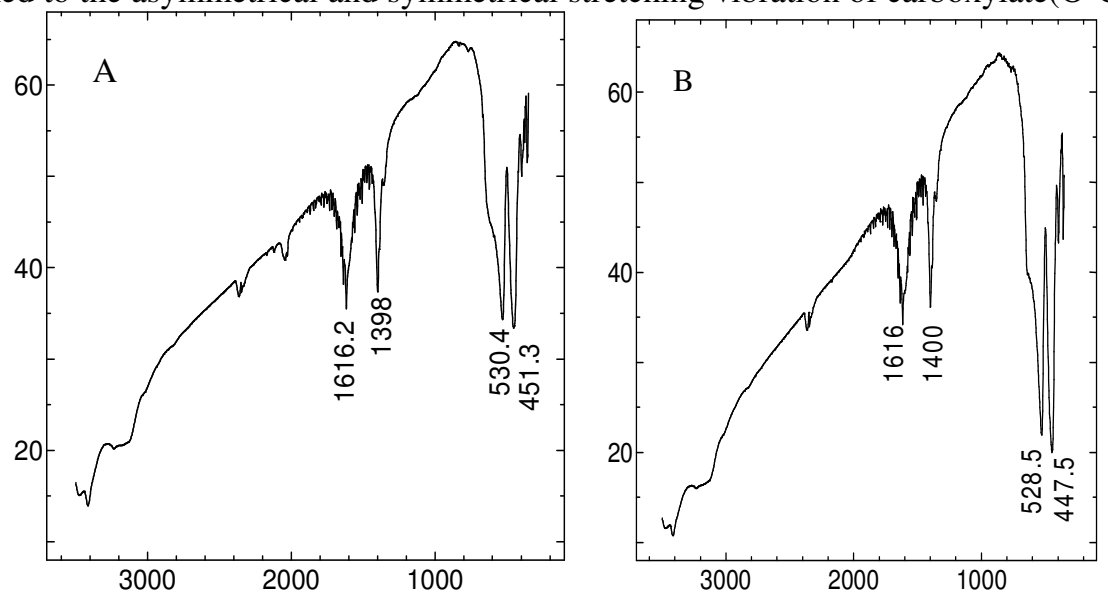

Figure 5. FT-IR spectra for the obtained $\mathrm{Fe}_{2} \mathrm{O}_{3}$, (A) Obtained at $150{ }^{\circ} \mathrm{C}(\mathrm{B})$ obtained at $200{ }^{\circ} \mathrm{C}$

Till present, the formation mechanism of ferric oxides is unclear. For example, for the $\alpha-\mathrm{Fe}_{2} \mathrm{O}_{3}$ cubes, Bailey ${ }^{16}$ proposed the dissolution re-crystallization mechanism, i.e., at the 
beginning, rod-like particles of $\beta-\mathrm{FeOOH}$ were formed, and then $\beta-\mathrm{FeOOH}$ dissolved and re-crystallized to form $\alpha-\mathrm{Fe}_{2} \mathrm{O}_{3}$ cubes. While, Sugimoto et al. suggested that the formation of hematite pseudo cubic particles was ascribed to the specfic adsorption of chloride ions or ferric complexes to $\{012\}$, and the adsorption restrained the growth in the directions normal to $\{012\}$ face. Kandori et $a l^{3}$. proposed the aggregation mechanism of $\alpha-\mathrm{Fe}_{2} \mathrm{O}_{3}$ particles based on the porous structure of the spherical hematite ${ }^{17}$.

In this work, due to the existing of absorption peaks at 1616 and $1400 \mathrm{~cm}^{-1}$, the carbon element, from $\mathrm{Fe}(\mathrm{CN})_{6}{ }^{3-}$, should participate in the hydrothermal process, probably silimar to the reported work ${ }^{15}$ in which except for $\mathrm{Fe}\left(\mathrm{NO}_{3}\right)_{3} \cdot 9 \mathrm{H}_{2} \mathrm{O}$ and $\mathrm{Mg}\left(\mathrm{NO}_{3}\right)_{2} \cdot 6 \mathrm{H}_{2} \mathrm{O}, \mathrm{C}_{6} \mathrm{H}_{8} \mathrm{O}_{7} \cdot \mathrm{H}_{2} \mathrm{O}$ were used as raw materials to prepare $\mathrm{MgFe}_{2} \mathrm{O}_{4}$. Unfortunately, with present technique, we can not present a satisfied interpretation to our observed phenomena.

\section{Conclusions}

Leaf-shaped ferric oxide particles were prepared directly from the hydrothermal process of potassium ferricyanide $\left[\mathrm{K}_{3} \mathrm{Fe}(\mathrm{CN})_{6}\right]$ as has never been reported so far. Results obtained from SEM and XRD all strongly demonstrated that $\alpha-\mathrm{Fe}_{2} \mathrm{O}_{3}$ was formed by this mild hydrothermal process. FT-IR spectra also indicated the formation of $\mathrm{Fe}-\mathrm{O}$ and $\mathrm{C}-\mathrm{C}=\mathrm{O}$ bands, and suggested that carbon element existing in $\mathrm{Fe}(\mathrm{CN})_{6}{ }^{3-}$ participated in the hydrothermal process though the exact interpretation could not be achieved by the present technique. Presenting the leaf-shaped ferric oxides, and its preparation method as well, is the main contribution of this preliminary work.

\section{Acknowledgement}

This work was financially supported by the Doctor Fund of Hebei Normal University (130301), Key Project of Hebei Province Education Bureau (140302) and Special Assistance Project of Hebei Province Personnel Bureau (106115).

\section{References}

1. McCurrie R A in: Ferromagnetic Materials, Structure and Properties, Academic Press, 1994, p. 171.

2. Sugimoto T, Muramatsu A, Sakata K and Shindo D, J Colloid Interface Sci., 1992, 152, 587.

3 Sugimoto T, Muramatsu A, Sakata K and Shindo D, J Colloid Interface Sci., 1993, 159, 372.

$4 \quad$ Kandori K, Okamoto N and Ishikawa T, Langmuir, 2002, 18, 2895.

5 Kan S, Zhang X, Yu S, Li D, Xiao L, Zou G, Li T, Dong W and Lu Y, J Colloid Interface Sci., 1997, 191, 503.

$6 \quad$ Kandori K and Ishikawa T, J Colloid Interface Sci., 2004, 272, 246.

7 Sugimoto T and Muramatsu A, J Colloid Interface Sci., 1996, 184, 626.

8 Sosa E, Cabrera-Sierra R, Oropeza M T, Hernández F, Casillas N, Tremont R, Cabrera C and González I, Electrochim Acta, 2003, 48, 1665.

9 Zheng Y H, Cheng Y, Bao F and Wang Y S, Mater Res Bull., 2006, 41, 525.

10 Šarić A, Nomura K, Popović S, Ljubešić N and Musić S, Mater Chem Phys., 1998, 52, 214.

11 Zhang D F, Sun L D, Jia C J, Yan Z G, You L P and Yan C H, J Am Chem Soc., 2005, 127, 13492. 
12 Lai J, Shafi K V P M, Loos K, Ulman A, Lee Y, Vogt T and Estournès C, J Am Chem Soc., 2003, 125, 11470.

13 Hou B, Wu Y, Wu L, Shi Y, Zou K and Gai H, Mater Lett., 2006, 60, 3188.

14 Chiu W S, Radiman S, Abdullah M H, Khiew P S, Huang N M and Abd-Shukor R, Mater Chem Phys., 2007, 106, 231.

15 Huang Y, Tang Y, Wang J and Chen Q, Mater Chem Phys., 2006, 97, 394.

16 Bailey J K, Brinker C J and Mecartney M L, J Colloid Interface Sci., 1993, 157, 1.

17 Kandori K, Kawashima Y and Ishikawa T, Chem Soc Faraday Trans., 1991, 87, 2241. 


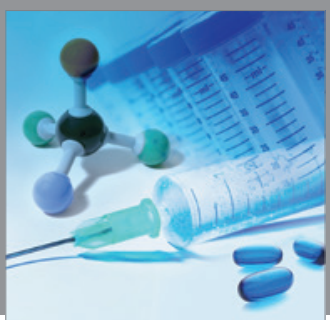

International Journal of

Medicinal Chemistry

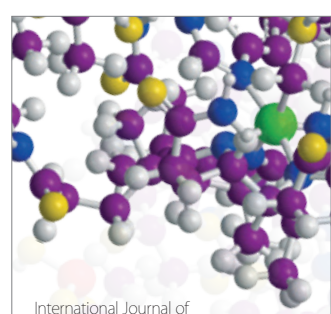

Carbohydrate Chemistry

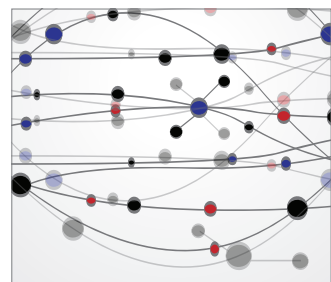

The Scientific World Journal
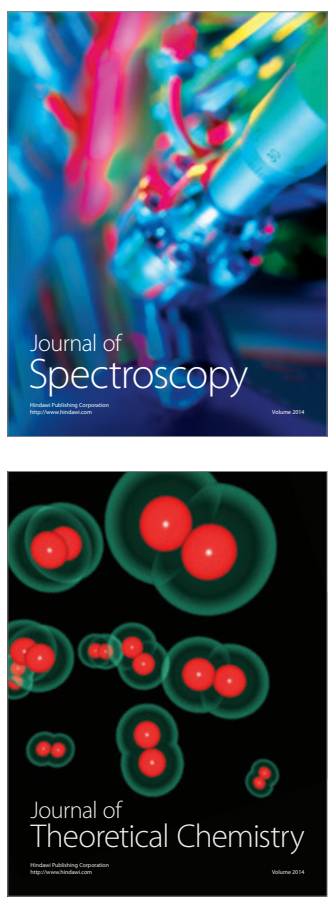
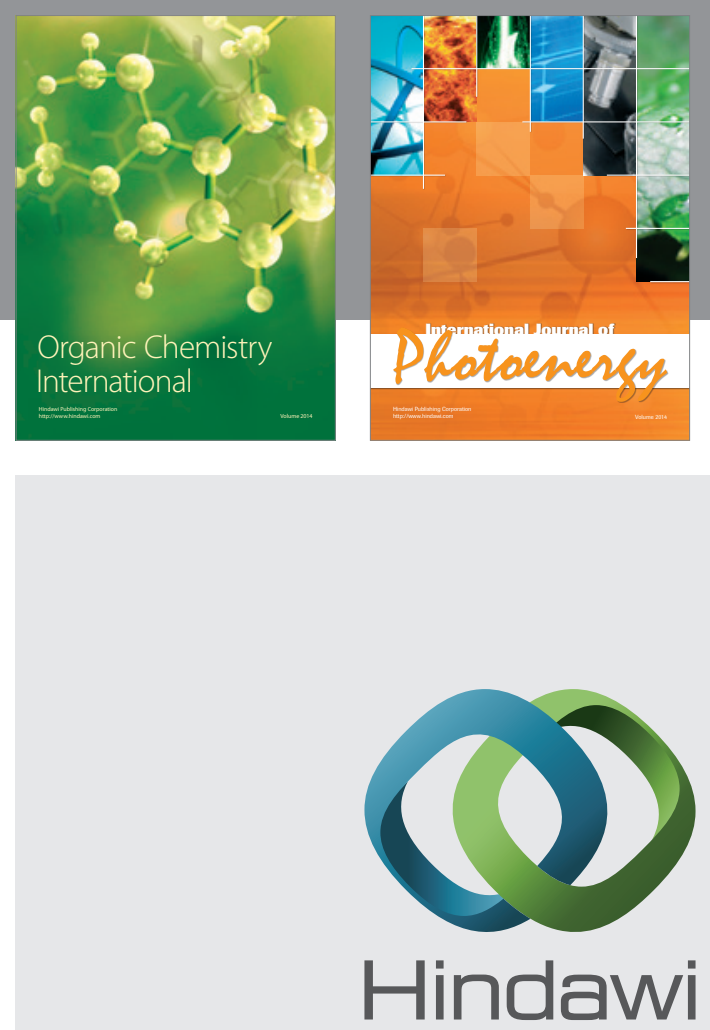

Submit your manuscripts at

http://www.hindawi.com
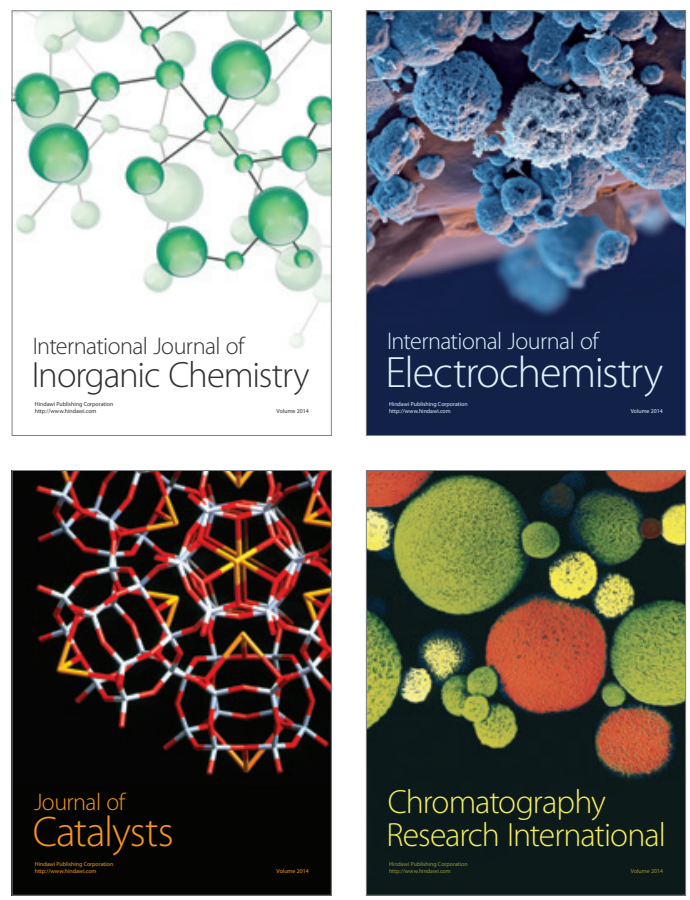
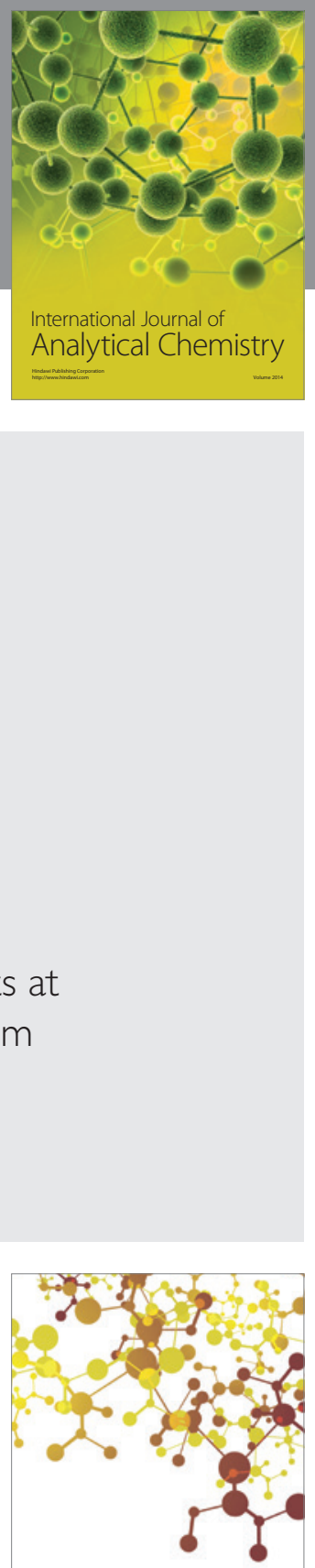

Journal of

Applied Chemistry
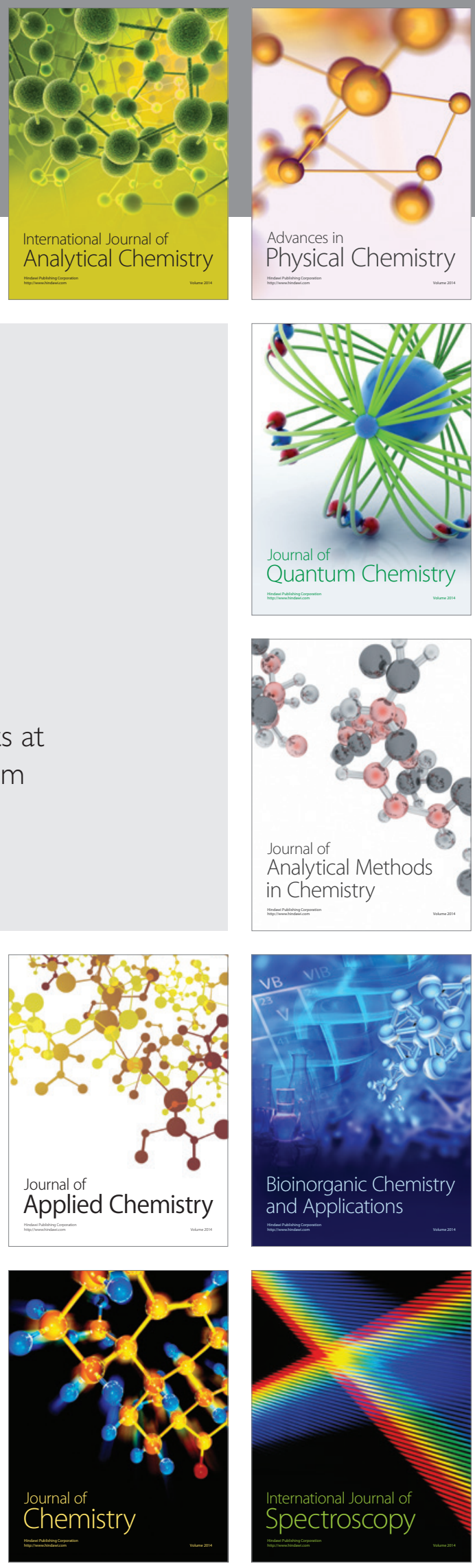